\title{
Multiple shoot induction and plant regeneration from axillary buds of Magnolia 'Vulcan'
}

\author{
Tae-Dong Kim $\cdot$ Ji-Ah Kim $\cdot$ Na-Nyum Lee $\cdot$ Chang-Ho Choi
}

Received: 29 January 2020 / Revised: 27 February 2020 / Accepted: 27 February 2020

(C) Korean Society for Plant Biotechnology

\begin{abstract}
An efficient protocol for multiple shoot induction and plant regeneration from axillary bud culture of Magnolia 'Vulcan' was developed in the present study. Primary shoots were obtained from axillary bud explants cultured on Murashige and Skoog (MS) medium containing $1.0 \mathrm{mg} / \mathrm{L}$ 6-benzylaminopurine (BA). To induce multiple shoots effectively, primary shoot tips were cultured on MS medium supplemented with different concentrations of BA and zeatin at $0,0.2,0.5$, and $1.0 \mathrm{mg} / \mathrm{L}$. Of these treatments, the MS medium with $0.5 \mathrm{mg} / \mathrm{LBA}$ resulted in the highest number of shoots per explant with an average value of 5.9, and it produced the greatest shoot height at $4.8 \mathrm{~cm}$ after 12 weeks of culturing. In the rooting of in vitro produced shoots, the greatest percentage of explants forming roots $(91.3 \%)$, number of roots per explant $(9.7)$, and root length $(2.8 \mathrm{~cm})$ were obtained in half-strength MS medium supplemented with $6.0 \mathrm{mg} / \mathrm{L}$ indole-3-butyric acid (IBA). Regenerated plantlets were successfully acclimatized and hardened off inside the culture room with $87.5 \%$ survival rate. Plants were transferred to a greenhouse with a $97.2 \%$ survival rate. The highly efficient shoot multiplication and plant regeneration system reported herein can be used for large-scale clonal propagation of valuable Magnolia species or cultivars.
\end{abstract}

Keywords Magnolia 'Vulcan', tissue culture, shoot multiplication, root induction, BA, IBA

\section{Introduction}

Magnolia species are one of the most glamorous ornamental

T. D. $\operatorname{Kim}(\bowtie) \cdot$ J. A. Kim $\cdot$ N. N. Lee

Forest Biotechnology Division, National Institute of Forest

Science, Suwon 16631, Korea

e-mail: ktd747@korea.kr

C. H. Choi

Department of Planning \& Education \& Research, Chollipo

Arboretum, Taean-Gun 32121, Korea landscape plants. One of the darkest red magnolias, 'Vulcan', is a striking deciduous shrub and elegant tree with rich, ruby-red flowers. 'Vulcan' is a hybrid between a M. liliiflora hybrid and M. campbellii 'Lanarth', and is a cultivar gaining popularity in gardens. As demand for 'Vulcan' is increasing, the continuous supply of its propagules is necessary.

Magnolias are sexually propagated from seeds and asexually from vegetative tissue. Vegetative propagation through cuttings is used to multiply clonal plants of valuable species and cultivars of Magnolia. Mass propagation of magnolias is difficult because the germination rate of seeds is relatively low and cuttings often have poor rooting ability (Callaway 1994; Ming and Huan-Cheng 2003). In vitro culture techniques provide an opportunity for large-scale clonal propagation of Magnolia species or cultivars that are difficult to produce by conventional methods.

In general, plant regeneration systems through in vitro culture using apical or axillary buds are the most applicable method for clonal plant propagation. Bud culture techniques have been successfully applied for the clonal propagation of some species, including Stevia rebaudiana, Citrus reticulate, and Enicostema axillare (Rangappa and Aind 2013; Shende and Manik 2015; Sasidharan and Jayachitra 2017). In Magnolia species or cultivars such as $M$. sirindhorniae, M. 'Ann', M. obovata, $M$. stellata, $M . \times$ liliiflora 'Nigra', and $M . \times$ soulangiana 'Coates', efficient methods for clonal multiplication have been developed using apical or axillary bud cultures (Chaidaroon et al. 2004; Parris et al. 2010; Ana-Maria 2012; Sokolov et al. 2014; Wojtania et al. 2015). However, there have been no reports about clonal propagation using tissue culture methods for $M$. 'Vulcan'.

The aim of the current study was to optimize a protocol for efficient multiple shoot induction and plant regeneration from axillary buds of $M$. 'Vulcan'. 


\section{Materials and Methods}

Plant materials

Axillary buds used as explants for in vitro shoot induction were taken from $M$. 'Vulcan' growing at the Chollipo Arboretum in Korea. Stem explants (3 4 cm long), each containing a node and axillary bud, were sterilized in $70 \%$ ethanol for $1 \mathrm{~min}$, disinfected in 3\% sodium hypochlorite solution for $20 \mathrm{~min}$, and rinsed five times in sterile distilled water.

Initiation of shoots from axillary buds

To initiate shoots from axillary buds, nodal segments (approximately $2 \mathrm{~cm}$ ) containing a single axillary bud were inoculated in MS (Murashige and Skoog, 1962) basal medium supplemented with $1.0 \mathrm{mg} / \mathrm{L} \mathrm{BA}$ (6-benzyladenine) and $3 \%$ sucrose. Media were solidified with $0.3 \%$ gelrite powder and adjusted to $\mathrm{pH} 5.8$ before autoclaving for $15 \mathrm{~min}$ at $121^{\circ} \mathrm{C}$. After inoculation, cultures were incubated at $25 \pm 2^{\circ} \mathrm{C}$ under a 16-h photoperiod with a light intensity of 2,000 lux under white fluorescent tubes.

Effect of cytokinins (BA or zeatin) on shoot multiplication

The apical portion of the shoot obtained in the initiation phase was used for multiple shoot induction. Excised shoot tip explants were placed on MS medium supplemented with various concentrations $(0.2,0.5$, and $1.0 \mathrm{mg} / \mathrm{L})$ of BA or zeatin. Ten explants were established for each treatment. Each treatment was replicated three times. After 8 weeks of culture, the number of shoots per explant was recorded.

Effect of auxin (IBA) and strength of basal medium salts on in vitro rooting

For rooting, shoots approximately $2 \mathrm{~cm}$ in length were excised and placed vertically on MS medium supplemented with various concentrations $(0.0,1.0,2.0,4.0,6.0,8.0$, and $10.0 \mathrm{mg} / \mathrm{L}$ ) of IBA (Indole-3-butyric acid). To investigate the effect of basal medium salt concentrations on root induction, microshoots were cultured on full-, half-, and one-third-strength MS medium with $6 \mathrm{mg} / \mathrm{L}$ IBA. Ten explants were established for each treatment. Each treatment was replicated three times. After 8 weeks of culture, rooting percentage, mean number of roots, and mean root length were recorded.

\section{Acclimatization}

Well-developed plantlets with roots were transplanted to plastic containers $(54 \times 28 \times 6.5 \mathrm{~cm})$ containing artificial soil mixture [perlite, vermiculrite, peatmoss 1:1:1 (v/v)] and were acclimated for 4 weeks at high relative humidity (80-90\%). After 4 weeks, survival rates were measured. Twenty plants were planted in soil and each experiment was performed three times. Acclimated plants were in plastic pots and transferred to the greenhouse.

Statistical analysis

Statistical analysis was performed according to the SAS system (SAS Enterprise Guide 7.1). Means and standard errors were used throughout and the statistical significance of mean values was assessed using ANOVA or Duncan's multiple range tests at $P<0.05$.

\section{Results and Discussion}

Shoot multiplication

For initiation of primary shoots from axillary buds, explants were inoculated in MS medium supplemented with 1.0 $\mathrm{mg} / \mathrm{L}$ BA. Explants cultured on the media showed axillary bud emergence and sprouting after $1 \sim 2$ weeks of culture (Fig. 1A). Primary shoots were obtained after 6 weeks of culture (Fig. 1B); the shoot tips were then used for further multiplication.

To induce multiple shoots effectively, excised shoot tip explants were cultured on MS medium supplemented with

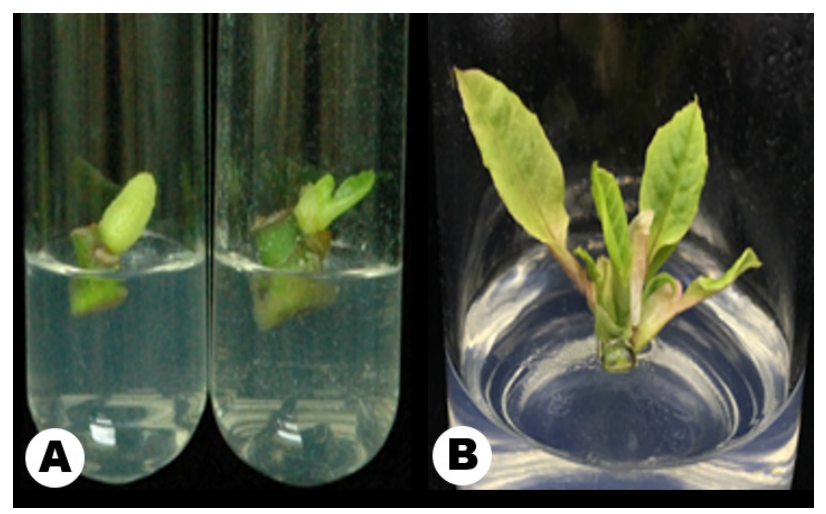

Fig. 1 The initiation of primary shoots from axillary buds of Magnolia 'Vulcan' on Murashige and Skoog (MS) medium supplemented with $1.0 \mathrm{mg} / \mathrm{L}$ 6-benzylaminopurine (BA). (A) Axillary bud emergence and sprouting after 2 weeks of culture. (B) Axillary shoot induction after 6 weeks of culturing 
Table 1 Effect of different types and concentrations of cytokinins on multiple shoot induction from shoot tip explants in Magnolia 'Vulcan' after 8 weeks of culturing

\begin{tabular}{ccc}
\hline $\begin{array}{c}\text { Cytokinin } \\
(\mathrm{mg} / \mathrm{L})\end{array}$ & $\begin{array}{c}\text { Average number of shoots } \\
\text { per explant }\end{array}$ & $\begin{array}{c}\text { Length of shoots } \\
(\mathrm{cm})\end{array}$ \\
\hline $\begin{array}{c}\text { Control } \\
\text { (growth regulator-free) }\end{array}$ & $1.0 \pm 0.0 \mathrm{~d}^{*}$ & $3.4 \pm 0.2 \mathrm{c}$ \\
BA 0.2 & $3.2 \pm 0.2 \mathrm{c}$ & $3.9 \pm 0.2 \mathrm{bc}$ \\
BA 0.5 & $5.9 \pm 0.4 \mathrm{a}$ & $4.8 \pm 0.3 \mathrm{a}$ \\
BA 1.0 & $5.1 \pm 0.4 \mathrm{~b}$ & $4.3 \pm 0.2 \mathrm{ab}$ \\
zeatin 0.2 & $1.0 \pm 0.0 \mathrm{~d}$ & $4.6 \pm 0.3 \mathrm{ab}$ \\
zeatin 0.5 & $1.0 \pm 0.0 \mathrm{~d}$ & $4.9 \pm 0.2 \mathrm{a}$ \\
zeatin 1.0 & $1.0 \pm 0.0 \mathrm{~d}$ & $4.8 \pm 0.3 \mathrm{a}$ \\
\hline
\end{tabular}

*Mean separation within columns by Duncan's multiple range test at $5 \%$ level.

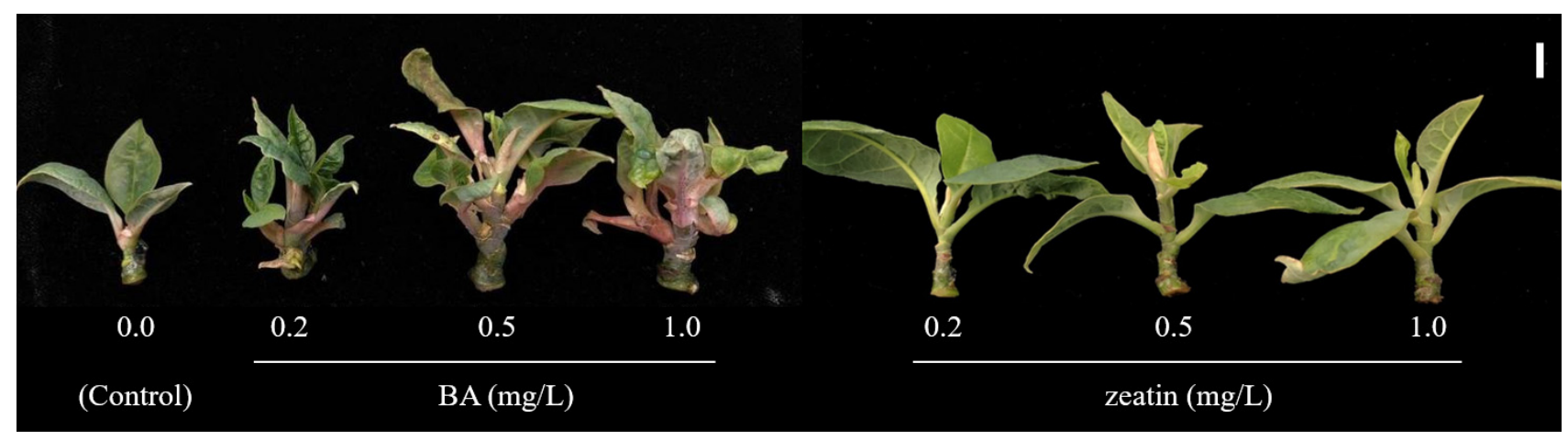

Fig. 2 Multiple shoot formation from apical tips of Magnolia 'Vulcan' cultured on Murashige and Skoog (MS) medium containing various concentrations of 6-benzylaminopurine (BA) or zeatin after 2 months of culturing. Bar $=1 \mathrm{~cm}$

different concentrations of BA or zeatin $(0.0,0.2,0.5$, and $1.0 \mathrm{mg} / \mathrm{L})$. As shown in Table 1 , there were significant differences between BA and zeatin regarding the number of shoots per explant. However, no significant differences were observed in shoot lengths. The highest number of shoots per explant (5.9) was observed in the medium containing $0.5 \mathrm{mg} / \mathrm{L}$ BA. The lowest concentration of BA $(0.2 \mathrm{mg} / \mathrm{L})$ displayed the lowest number of shoots (3.2). No formation of multiple shoots was seen in the presence of zeatin. Multiple shoots were not induced from shoot tip explants cultured on MS medium supplemented with various concentrations of zeatin. Therefore, BA performed better in multiple shoot induction from shoot tip explants than did zeatin. Thus, BA has a significant beneficial effect on multiple shoot induction of $M$. 'Vulcan' with an optimal concentration of $0.5 \mathrm{mg} / \mathrm{L}$.

The formation of multiple shoots from shoot tip explants was observed in MS medium supplemented with BA (Fig. 2 ). The main shoot and axillary buds grew actively and developed into multiple shoots after 8 weeks of culture. Defoliation from the explant was also observed during this period. Unlike BA, the addition of zeatin in the medium failed to show good shoot multiplication responses as the main shoot grew actively, but axillary buds did not grow into new shoots. During this period, defoliation from the explant was not observed. These results indicate that BA promotes axillary buds to grow a lateral shoot, whereas zeatin promotes shoot elongation, but not shoot multiplication, in $M$. 'Vulcan'.

Cytokinins have been used to induce multiple shoots from explants, including shoot tip and node explants. The types and concentrations of cytokinin suitable for stimulation of shoot multiplication tend to show different responses depending on the species, including Stevia rebaudiana, Citrus reticulate, and Enicostema axillare (Rangappa and Aind 2013; Shende and Manik 2015; Sasidharan and Jayachitra 2017). Here, there were significant differences in the effect of different cytokinin types (BA or zeatin) and their concentrations on shoot multiplication from shoot tips of $M$. 'Vulcan'. The greatest multiple shoot induction from shoot tip explants resulted from $0.5 \mathrm{mg} / \mathrm{L} \mathrm{BA}$, whereas zeatin at every concentration did not promote shoot multiplication. Similarly, Parris et al. (2010) reported that shoot number was higher on media containing $0.5 \mathrm{mg} / \mathrm{L} \mathrm{BA}$, 
while other cytokinins (mT and 2iP) did not promote shoot proliferation in M. 'Ann'. Radomir (2012) reported that $0.5 \mathrm{mg} / \mathrm{L}$ BA was the most effective concentration for shoot multiplication from apical buds of $M$. stellate and $M . \times$ soulangiana compared to other cytokinins (2iP, TDZ, and kinetin). Wojtania et al. (2015) reported that a concentration of $0.2 \mathrm{mg} / \mathrm{L} \mathrm{BA}$ resulted in the greatest multiple shoot induction from apical and axillary buds of $M . \times$ soulangiana 'Coates'. These results indicate that BA is a crucial growth regulator in shoot multiplication from apical or axillary buds, and its proper concentration varies depending on Magnolia species.

In vitro rooting

When in vitro-elongated shoots (Fig. 3A) were cultured on
MS medium supplemented with different concentrations $(0.0,1.0,2.0,4.0,6.0,8.0$, and $10.0 \mathrm{mg} / \mathrm{L})$ of IBA, the appearance of the first primary root was observed after 2-3 weeks of culture. As shown in Table 2, there were significant differences in rooting percentage, number of roots per explant, and root length among the different concentrations of IBA. After 6 weeks of culture, the highest rooting percentages $(84.7 \%)$ and numbers of roots per explant (8.2) were obtained when the shoots were cultured on MS medium containing $6 \mathrm{mg} / \mathrm{L}$ IBA. The greatest root length $(2.9 \mathrm{~cm})$ was measured when MS medium was supplemented with $4 \mathrm{mg} / \mathrm{L}$ IBA. In MS medium lacking IBA, in vitro rooting of shoots was not observed. These results suggest that IBA promotes in vitro root formation in $M$. 'Vulcan' and the optimal concentration is $6.0 \mathrm{mg} / \mathrm{L}$. To investigate the effect of basal medium salt con-

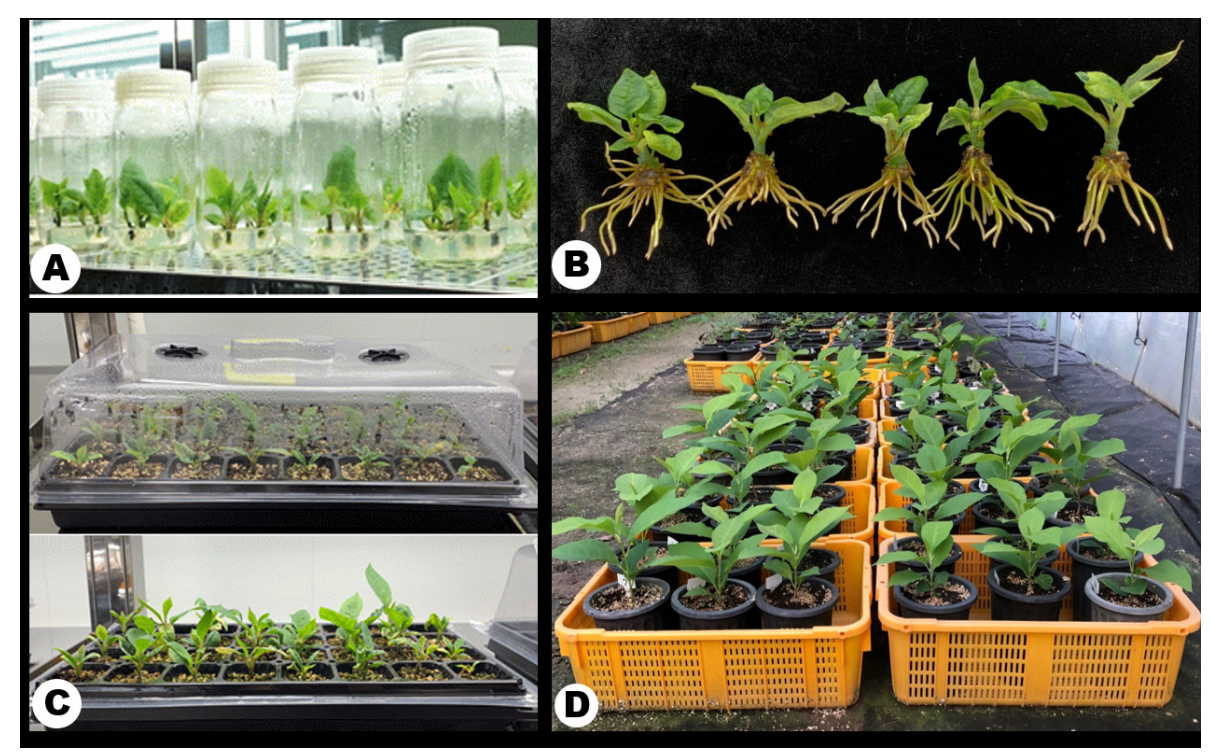

Fig. 3 Efficient in vitro rooting and ex vitro acclimatization of Magnolia 'Vulcan'. (A) Shoots cultured on half-strength Murashige and Skoog (MS) medium containing $6.0 \mathrm{mg} / \mathrm{L}$ indole-3-butyric acid (IBA) for root induction. (B) Regenerated young plantlets with well-developed roots after 6 weeks of culturing. (C) Plants acclimatized in plastic containers containing soil for 4 weeks. (D) Cultivation of potted plants in the greenhouse

Table 2 Effect of different concentrations of indole-3-butyric acid (IBA) on in vitro rooting of elongated shoots in Magnolia 'Vulcan' after 8 weeks of culturing

\begin{tabular}{cccc}
\hline $\begin{array}{c}\text { Concentration of IBA } \\
(\mathrm{mg} / \mathrm{L})\end{array}$ & $\begin{array}{c}\text { Rooting } \\
(\%)\end{array}$ & $\begin{array}{c}\text { No. of roots per } \\
\text { explant }\end{array}$ & $\begin{array}{c}\text { Length of root } \\
(\mathrm{cm})\end{array}$ \\
\hline 0.0 & $0.0 \mathrm{~d}^{*}$ & $0.0 \mathrm{~d}$ & $0.0 \mathrm{~d}$ \\
1.0 & $9.5 \pm 0.4 \mathrm{~d}$ & $2.6 \pm 0.2 \mathrm{c}$ & $1.9 \pm 0.3 \mathrm{bc}$ \\
2.0 & $12.3 \pm 0.6 \mathrm{~d}$ & $4.7 \pm 0.6 \mathrm{~b}$ & $2.7 \pm 0.4 \mathrm{ab}$ \\
4.0 & $47.1 \pm 0.5 \mathrm{~b}$ & $5.4 \pm 0.5 \mathrm{~b}$ & $2.9 \pm 0.3 \mathrm{a}$ \\
6.0 & $84.7 \pm 0.4 \mathrm{a}$ & $8.2 \pm 0.6 \mathrm{a}$ & $2.4 \pm 0.2 \mathrm{abc}$ \\
8.0 & $57.5 \pm 0.6 \mathrm{~b}$ & $6.1 \pm 0.5 \mathrm{~b}$ & $1.9 \pm 0.2 \mathrm{bc}$ \\
10.0 & $34.6 \pm 0.5 \mathrm{c}$ & $5.1 \pm 0.4 \mathrm{~b}$ & $1.5 \pm 0.2 \mathrm{c}$ \\
\hline
\end{tabular}

*Mean separation within columns by Duncan's multiple range test at $5 \%$ level. 
Table 3 Effect of Murashige and Skoog (MS) basal medium salt strength with $6 \mathrm{mg} / \mathrm{L}$ indole-3-butyric acid (IBA) on in vitro rooting of elongated Magnolia 'Vulcan' shoots after 8 weeks of culturing

\begin{tabular}{cccc}
\hline Strength of medium salts & $\begin{array}{c}\text { Rooting } \\
(\%)\end{array}$ & $\begin{array}{c}\text { No. of roots per } \\
\text { explant }\end{array}$ & $\begin{array}{c}\text { Length of root } \\
(\mathrm{cm})\end{array}$ \\
\hline Full-strength MS (control) & $85.6 \pm 0.5 \mathrm{a}^{*}$ & $8.5 \pm 0.4 \mathrm{ab}$ & $2.4 \pm 0.2 \mathrm{a}$ \\
Half-strength MS & $91.3 \pm 0.4 \mathrm{a}$ & $9.7 \pm 0.5 \mathrm{a}$ & $2.8 \pm 0.2 \mathrm{a}$ \\
One-third-strength MS & $88.1 \pm 0.6 \mathrm{a}$ & $7.2 \pm 0.4 \mathrm{~b}$ & $1.6 \pm 0.1 \mathrm{~b}$ \\
\hline
\end{tabular}

*Mean separation within columns by Duncan's multiple range test at $5 \%$ level.

Table 4 The hardening and acclimatization of propagated in vitro Magnolia 'Vulcan' plantlets

\begin{tabular}{ccccc}
\hline Stage & $\begin{array}{c}\text { Survival } \\
(\%)\end{array}$ & $\begin{array}{c}\text { Height } \\
(\mathrm{cm})\end{array}$ & $\begin{array}{c}\text { Length of root } \\
(\mathrm{cm})\end{array}$ & $\begin{array}{c}\text { Fresh weight } \\
(\mathrm{g})\end{array}$ \\
\hline Acclimatized plants & $87.5 \pm 0.5$ & $6.3 \pm 0.2$ & $10.3 \pm 0.3$ & $4.1 \pm 0.2$ \\
Potted plants & $97.2 \pm 0.4$ & $9.7 \pm 0.2$ & $24.4 \pm 0.5$ & $6.4 \pm 0.1$ \\
\hline
\end{tabular}

centration on root induction, in vitro-elongated shoots were cultured on full-, half-, and one-third-strength MS medium with $6 \mathrm{mg} / \mathrm{L}$ IBA. As shown in Table 3, there were no significant differences in percentage of rooting among the different salt strengths. The rooting percentage of shoots cultured on half-strength MS medium with $6 \mathrm{mg} / \mathrm{L} \mathrm{IBA}$ was slightly higher $(91.3 \%)$ than shoots cultured on onethird- and full-strength MS medium with $6 \mathrm{mg} / \mathrm{L}$ IBA (88.1\% and $85.6 \%$, respectively). The greatest number of roots (9.7) and root length $(2.8 \mathrm{~cm})$ per explant were observed in half-strength MS medium with $6 \mathrm{mg} / \mathrm{L} \mathrm{IBA}$. Consequently, half-strength MS medium with $6 \mathrm{mg} / \mathrm{L} \mathrm{IBA}$ showed the greatest percentage of explants forming roots, number of roots per explant, and length of roots in $M$. 'Vulcan'.

Successful rooting of in vitro-produced shoots is crucial for facilitating field establishment of micropropagated plants. Supplementation of auxins and the strength of basal medium salts is considered important for rooting of shoots. Auxin plays a critical role in inducing adventitious rooting in many plants. In particular, IBA is widely used for inducing adventitious root formation from in vitro-raised shoots of some species, including Prunus dulcis, P. cerasus, Dendrocalamus hamiltonii, and Pyrus elaeagrifolia (Tereso et al. 2008; Agnihotri and Nandi 2009; Sarropoulou et al. 2013; Aygun and Dumanoglu 2015). In Arabidopsis thaliana, Fattorini et al. (2017) reported that IBA promotes adventitious rooting in thin cell layers by converting IBA into indole3 -acetic acid (IAA). In vitro rooting of shoots in some species, such as Cattleya and Passiflora foetida, is promoted when the overall salt strength of MS medium was reduced (Dewir et al. 2015; Shekhawat et al. 2015). On the other hand, AbdAlla and Mostafa (2015) reported that full-strength MS medium resulted in good rooting of in vitro-cultured microshoots of Rubus fruticosus. These results indicate that the effect of MS medium salt strength on rooting of shoots may vary between plant species. In some Magnolia species (M. stellate, M. sirindhorniae Noot. \& Chalermglin, and M. soulangiana), full- or half-strength MS medium supplemented with IBA alone was used for successful rooting and the optimal concentration of IBA was $4.0 \mathrm{mg} / \mathrm{L}$ (Kamenicka and Lanakova 2000; Chaidaroon et al. 2004; Radomir 2012). In the present study, different concentrations of IBA had significant effects on rooting of shoots in $M$. 'Vulcan'. In vitro rooting was the most effective when shoots were cultured in half-strength MS medium supplemented with $6.0 \mathrm{mg} / \mathrm{L} \mathrm{IBA}$. At higher concentrations of IBA (up to $10.0 \mathrm{mg} / \mathrm{L}$ ), the rooting percentage decreased. Thus, the optimal IBA concentration for rooting of in vitro-produced shoots may vary between Magnolia species ranging from 4.0 to $6.0 \mathrm{mg} / \mathrm{L}$.

\section{Acclimatization}

The rooted plantlets (Fig. 3B), approximately $2 \sim 4 \mathrm{~cm}$ in height, were transferred into plastic containers containing artificial soil for acclimatization. Because high atmospheric humidity is very important for plant survival, the plantlets were covered with plastic caps for approximately 4 weeks to maintain approximately $90 \%$ relative humidity (Fig. 3C). The regenerated plantlets were successfully acclimatized and hardened off inside the culture room and showed an $87.5 \%$ survival rate (Table 4). The acclimatized plants grew to $6.3 \mathrm{~cm}$ in height. Plants were transferred to a greenhouse after 3 months with a $97.2 \%$ survival rate and grew to $9.7 \mathrm{~cm}$ in height (Table 4, Fig. 3D).

In conclusion, the present study showed that for shoot multiplication, BA was highly efficient at inducing multiple shoots from axillary buds of $M$. 'Vulcan' and its optimal 
concentration was $0.5 \mathrm{mg} / \mathrm{L}$. Furthermore, during plant regeneration, optimal root formation was found when in vitro-produced shoots were cultured on half-strength MS medium supplemented with $6.0 \mathrm{mg} / \mathrm{L}$ IBA. The highly efficient shoot multiplication and regeneration system for M. 'Vulcan' reported here can be used for large-scale propagation of clonal plants.

\section{References}

Agnihotri RK, Nandi SK (2009) In vitro Shoot Cut: A high frequency multiplication and rooting method in the Bamboo Dendrocalamus hamiltonii. Biotechnology 8:259-263

Ana-Maria R (2012) Comparative study on the in vitro multiplication potential of Magnolia stellate and Magnolia $\times$ soulangiana species. Journal of Horticulture, Forestry and Biotechnology 16(2):39-44

AbdAlla MM, Mostafa RAA (2015) In Vitro Propagation of Blackberry (Rubus fruticosus L.) Assiut J. Agric. Sci., 46(3): 88-99

Aygun A, Dumanoglu H (2015) In vitro shoot proliferation and in vitro and ex vitro root formation of Pyrus elaeagrifolia Pallas. Front Plant Sci. 6:225

Chaidaroon S, Ungvichian I, Ratanathavornkiti (2004) In vitro root initiation of 'Champi Sirindhorn'(Magnolia sirindhorniae Noot. \& Chalermglin). AU J. T. 129-132

Callaway D (1994) Magnolias. London: B.T. Batsford Ltd. 260 p

Dewir YH, El-Mahrouk ME, Niranjana Murthy HN, Paek KY (2015) Micropropagation of Cattleya: Improved In Vitro Rooting and Acclimatization. Hort. Environ. Biotechnol. 56(1):89-93

Fattorini L, Veloccia A, Della Rovere F, D’Angeli S, Falasca G (2017) Indole-3-butyric acid promotes adventitious rooting in Arabidopsis thaliana thin cell layers by conversion into indole-3-acetic acid and stimulation of anthranilate synthase activity. BMC Plant Biology 17:121

Kamenicka A, Lanakova M (2000) Effect of medium composition and type of vessel closure on axillary shoot production of magnolia in vitro. Acta Physiologiae Plantarum 22:129-134

Ming L, Huan-Cheng MA (2003) The review of the asexual propagation on Magnoliaceae. J. Southwest Forestry College 23: $92-96$

Parris JK, Touchell DH, Ranney TG (2010) Optimizing in vitro growth conditions for Magnolia 'Ann'. SNA Research Conference 55:30-35

Rangappa K, Aind DS (2013) High frequency multiplication of shoots using axillary buds for production of elite lines of Stevia rebaudiana. Adv Biosci Biotechnol 4:781-784

Radomir A M (2012) Comparative study on the in vitro multiplication potential of Magnolia stellata and Magnolia $\times$ soulangiana species. J. Hort. Forest Biotechnol. 16: 39-44

Shekhawat MS, Kannan N, Manokari M, Ravindran CP (2015) In vitro regeneration of shoots and ex vitro rooting of an important medicinal plant Passiflora foetida L. through nodal segment cultures. Journal of Genetic Engineering and Biotechnology 13(2):209-214

Sokolov RS, Atanassova BY, Iakimova ET (2014) Physiological response of in vitro cultured Magnolia sp. to nutrient medium composition. Journal of Horticultural Research 22(1):49-61

Sarropoulou V, Dimassi-Theriou K, Therios I (2013) Indole-3-butyric acid and myo-inositol impacts on in vitro rooting of the cherry rootstocks CAB-6P and Gisela 6. Biologia Plantarum 57: 613-619

Shende CB, Manik SR (2015) Direct regeneration of shoot from axillary bud of Citrus reticulate. Journal of Agricultural Technology 11(6):1401-1409

Sasidharan P, Jayachitra A (2017) Direct shoot bud regeneration from shoot tip explants of Enicostema axillare: an important medicinal plant. Agroforestry Systems 91:471-477

Tereso S, Miguel CM, Mascarenhas M, Roque A, Trindade H, Maroco J, Oliveira MM (2008) Improved in vitro rooting of Prunus dulcis Mill. Cultivars. Biologia Plantarum 52(3): 437-444

Wojtania A, Skrzypek E, Gabryszewska E (2015) Effect of cytokinin sucrose and nitrogen salts concentrations on the growth and development and phenolics content in Magnolia $\times$ soulangiana 'Coates' shoots in vitro. Acta Sci. Pol. Hortorum Cultus 14(3):51-62 